\title{
An inventory of biomedical imaging physics elements-of-competence for diagnostic radiography education in Europe
}

\author{
Carmel J. Caruana $^{\mathrm{a}, *}$, Jaromir Plasek ${ }^{\mathrm{b}}$ \\ a University of Malta, Institute of Health Care, St Lukes Hospital, Gwardamangia, Malta \\ ${ }^{b}$ Charles University, Faculty of Mathematics and Physics, Institute of Physics, Division of Biophysics, \\ Prague, Czech Republic
}

Received 5 May 2005; accepted 21 July 2005

Available online 8 September 2005

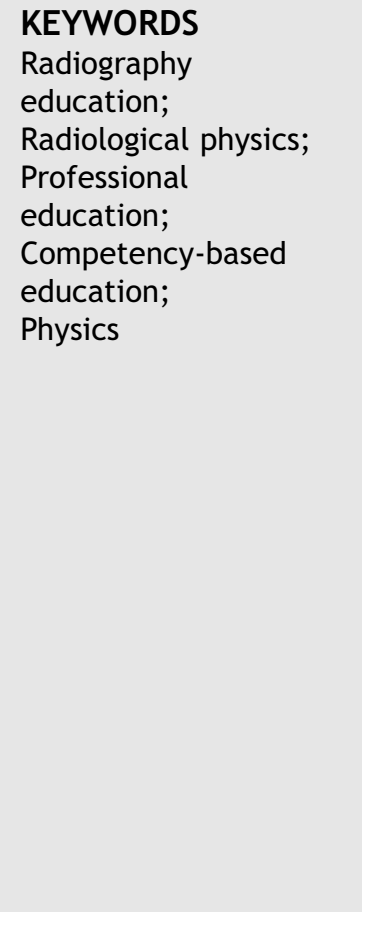

\begin{abstract}
Purpose To develop an inventory of biomedical physics elements-ofcompetence for diagnostic radiography education in Europe.

Method Research articles in the English literature and UK documentation pertinent to radiography education, competences and role development were subjected to a rigorous analysis of content from a functional and competence analysis perspective. Translations of radiography curricula from across Europe and relevant EU legislation were likewise analysed to ensure a pan-European perspective. Broad Subject Specific Competences for diagnostic radiography that included major biomedical physics components were singled out. These competences were in turn carefully deconstructed into specific elements-of-competence and those elements falling within the biomedical physics learning domain inventorised. A pilot version of the inventory was evaluated by participants during a meeting of the Higher Education Network for Radiography in Europe (HENRE), held in Marsascala, Malta, in November 2004. The inventory was further refined taking into consideration suggestions by HENRE members and scientific, professional and educational developments.

Findings The evaluation of the pilot inventory was very positive and indicated that the overall structure of the inventory was sensible, easily understood and acceptable - hence a good foundation for further development.

Conclusions Use of the inventory by radiography programme leaders and biomedical physics educators would guarantee that all necessary physics elements-of-competence underpinning the safe, effective and economical use of imaging devices are included within radiography curricula. It will also ensure the relevancy of physics content within radiography education. The inventory is
\end{abstract}

\footnotetext{
* Corresponding author. Tel.: +356 99486920.

E-mail address: carmel.j.caruana@um.edu.mt (C.J. Caruana).
} 
designed to be a pragmatic tool for curriculum development across the entire range of radiography education up to doctorate level and irrespective of whether curriculum delivery is discipline-based or integrated, presentation-based or problem-based. It is suggested that the methodology used in the evolution of the inventory be applied to the development of inventories of elements-of-competence for other learning domains within health professional curricula.

๑ 2005 The College of Radiographers. Published by Elsevier Ltd. All rights reserved.

\section{Introduction}

Radiography is arguably one of the most device intensive of the health professions, yet surprisingly the role of the biomedical physics educator in schools of diagnostic imaging has historically not been well defined. The consequences have perhaps too often been learning objectives that are far removed from the everyday practicalities in the exercise of the profession and a low level of motivation on the part of the students. Meanwhile, the array, variety and complexity of imaging (and ancillary) devices have been increasing rapidly with the swift advances in healthcare technology. On the other hand, as imaging device physics education has not kept pace so have underutilization of imaging devices and the number of instances of improper use. This paper describes the development of an inventory of physics elementsof-competence designed specifically to provide guidance in the construction of the biomedical physics component of radiography curricula. It is based on a model of the biomedical physics educator role as a bridging and facilitating role spanning the divide between the physics knowledge base that underpins the effective, safe and economical use of medical devices and the practice oriented curricula of the health professions.

\section{Literature search}

A reasonably well developed body of literature exists on general aspects of curriculum development in radiography. ${ }^{1-8}$ There is, however, a quasitotal absence of articles regarding the biomedical imaging physics component. A search of the main health and education research databases in the English language using the search-word 'physics' resulted in very few relevant references. Some references were found concerning the teaching of physics to radiology residents. These mostly originate from the US and reveal a concern regarding the principles that should guide the selection of physics content within radiology curricula. ${ }^{9-12}$ The College of Radiographers (UK) has included sections on 'physical sciences' and 'technology' in its curricu- lum framework for radiography, ${ }^{1}$ however, given the of necessity broad nature of the document further specification is required to produce outcome statements that are directly usable in the educational environment. The European Federation of Medical Physics (EFOMP) has published in association with the European Association of Radiology (EAR) an imaging physics syllabus for radiology, ${ }^{13}$ whilst the American Association of Physicists in Medicine has published a guide for teaching physics to radiologists. ${ }^{14}$ Neither document is outcome or competence based and both are therefore not really consonant with modern curriculum design principles. ${ }^{15-17}$ Surprisingly neither organisation has published an equivalent document for radiographers notwithstanding the fact that the role of the radiographer invites a higher level of interaction with devices than that of the radiologist. Most schools of radiography publish a locally developed physics syllabus under such diverse names as 'radiation physics', 'principles of radiation science', 'imaging equipment', 'imaging science and instrumentation', 'radiation protection' and others, ${ }^{6}$ but there is little published evidence of a systematic and studied approach. A document published by the European Commission offers direction, however, competences are restricted to ionising radiation protection only. ${ }^{18}$ To the best of our knowledge, our study is therefore the first systematic and comprehensive study of the biomedical physics component of radiography curricula.

\section{The Bologna process and HENRE}

Meanwhile the Bologna process in Europe (which aims to establish a European Higher Education Area) is encouraging institutions involved in higher education to take a critical look at their curricula and ensure that the latter are more in agreement with the present and future learning needs of the professions. ${ }^{19}$ The Tuning Educational Structures in Europe initiative is promoting the active use of outcomes-driven curriculum development in which programme end-points are expressed in terms of the Generic Competences (Tuning terminology for cross-professional competences) and Subject 
Specific Competences (Tuning terminology for profession-specific competences) that students should acquire by the time they finish their studies. ${ }^{20}$ Such exit competences should be based on agreement with and in consultation with the various stakeholders. The Higher Education Network for Radiography in Europe (HENRE) has set as one of its main priorities the establishment of such an inventory of competences. ${ }^{21}$ Once an agreed list of competences has been established, it is then up to experts in the various disciplines within faculties of health science to translate these into specific elements-of-competence that would contribute in an integrated and interlaced way to programme and module outcomes. This paper seeks to establish the specific biomedical physics elements-of-competence that would support radiography Subject Specific Competences.

\section{Methodology}

The curriculum framework for radiography of the College of Radiographers (UK), ${ }^{1}$ the Health Professions Council (UK) Standards of Proficiency: Radiographers, ${ }^{22}$ the Quality Assurance Agency - Higher Education (UK) Radiography Benchmark Statement, ${ }^{4}$ the Skills-for-Health (UK) National Occupational Standards for Clinical Imaging (UK), ${ }^{23}$ the Knowledge and Skills Framework (NHS UK), ${ }^{24}$ and other documents and research journal articles, ${ }^{2,3,5-8,25-30}$ pertinent to radiography education, competences and role development were subjected to a rigorous analysis of content from a functional and competence analysis perspective. Curriculum documents were collected from HENRE members and others (see the list of contributors in the Acknowledgements section at the end of the paper) or trawled from the Internet, translated, and likewise scrutinised to ensure a Europe wide perspective. EU legislation having a direct impact on medical imaging devices or the role of the radiographer was also analysed. ${ }^{31-33}$ Broad Subject Specific Competences for Radiography that included major biomedical physics components were singled out. These broad competences were in turn deconstructed carefully into specific constituent elements-of-competence and those elements falling within the biomedical physics learning domain identified. A structured elements-of-competence inventory was designed with the aim of producing a practical curriculum development tool for radiography programme leaders and biomedical physics educators in Europe. A pilot version of the inventory was subjected to an initial questionnaire-based evaluation during an international HENRE meeting
(Marsascala, Malta, November 2004) to ensure that the overall framework was sensible, easily understood, acceptable and hence a suitable framework for further development. The inventory was then further developed and refined to take into consideration the suggestions of HENRE members and new scientific, professional and educational developments.

\section{Results}

The documentary analysis indicated that the aim of physics teaching within radiography education is to ensure that learners acquire the necessary physics elements-of-competence underpinning the following broad radiography Subject Specific Competences:

1. Understand the key concepts of the physical sciences that underpin medical imaging and be able to utilise them in their practice and research.

2. Be able to use medical imaging and any ancillary devices effectively, safely and economically within their specific scope-of-practice.

3. Be able to practice in accordance with legislation governing the use of radiation for medical imaging purposes.

4. Be able to audit, monitor and review the effectiveness, safety and economic aspects of practice and modify it accordingly.

5. Be able to carry out health technology assessments and develop new clinical applications for imaging devices.

In this context 'effectively' refers to the use of medical imaging devices for the production of images which include those target image quality outcomes (expressed in terms of 'image quality criteria') necessitated by the specific diagnostic or monitoring needs of particular client groups. ${ }^{34}$ The term 'safely' refers to the avoidance of unnecessary risk to clients and the total elimination or reduction to acceptable levels of risks to users, colleagues and others from physical health hazards when the device is in use. 'Physical health hazards' refers to ionising radiation, mechanical, electrical, acoustic, ultrasonic, magnetic, electromagnetic and elevated body temperature risks. Target safety outcomes are expressed in terms of 'safety criteria' (known as 'dose criteria' in the case of ionising radiation ${ }^{34}$ ). Examples of 'ancillary devices' are contrast media injectors, immobilization devices, dosemeters, ergonometers and radionuclide generators. It should be noted that 
software that is required for the functioning and effective use of a medical device (for example image reconstruction and processing software) is itself considered as a medical device and therefore a device ancillary to imaging devices. ${ }^{33}$ 'Audit, monitor and review' includes quality control of devices and adherence to safety standards (for example diagnostic reference levels and occupational dose limits in the case of ionising radiation). Curriculum development and delivery regarding these general competences necessitates a close collaborative effort between experts in the disciplines of biomedical physics, human biology (anatomy, physiology and pathology), imaging protocol design and clinical imaging practice. This paper targets the biomedical physics aspects.

\section{Analysis of European radiography curricula}

The analysis of the First Cycle curricula (Tuning terminology referring to the Bachelor (evel) and other documents, ${ }^{35,36}$ indicated three main approaches in terms of programme end-points. The first group of curricula are based on a wide scopeof-practice for projection radiography coupled with a restricted scope-of-practice in CT. Other imaging modalities are taught at a level where students learn to appreciate the diagnostic and monitoring capabilities of the medical imaging device, an awareness of risks to patient, self, colleagues and others from use of the device and the competences necessary for use of the device on test-objects and anthropomorphic phantoms. The curricula in the second group are based on a wide scope-of-practice for projection radiography followed by a form of specialization in a chosen imaging modality. A third group tends to favour an approach where all the commonly used imaging modalities are introduced early and there is an attempt at parallel development of student competence in all modalities. All three approaches can be accommodated in the inventory model promoted in this paper. In some countries radiographers are specifically expected to develop competence in the use of devices considered ancillary to imaging for example electrophysiology devices (France and Poland) and lithotripsers. Many Second Cycle curricula (Tuning terminology for Masters level) are modality specific (ultrasound, MRI or radionuclide imaging). Third Cycle (Ph.D.) programmes are research oriented and those that are device based may involve health technology assessment or the development of new clinical applications for the device. ${ }^{37}$

\section{Evaluation of the pilot version of the inventory}

Table 1 shows questions and responses in the evaluation of the pilot version of the inventory that we presented at the HENRE conference in Marsascala, Malta in November 2004. The questionnaire was designed for effective (in terms of evaluation objectives) yet rapid response owing to pressures on respondents' time. Questions were purposely dichotomous (yes/no alternatives) and rating scales were avoided. However, suggestions for improvements to the inventory were encouraged. Although members were not present from all EU countries, respondents covered the various regions of Europe (members from 14 countries responded, with an average of two respondents per country). The evaluation was very positive and indicated that the overall structure of the inventory was sensible, easily understood and acceptable and hence a good basis for further development. This claim was further supported by reports of the conference in the literature. ${ }^{38}$ Suggestions offered by participants were taken into consideration in the final version of the inventory.

\section{The inventory}

The final version of the inventory is attached as Appendix A to this paper. The first column of the table lists the statements of the elements-ofcompetence. The second column contains explanatory notes. These explanatory notes were added following a suggestion during the evaluation of the pilot inventory. The order of the elementsof-competence is meant to guide sequencing during curriculum delivery. The structure of the inventory and choice of the included elements-ofcompetence were guided by the following principles:

1. The inventory will be a pragmatic tool to guide curriculum development across the whole range of diagnostic radiography education.

2. Owing to the increasing pressures on the curriculum, only those biomedical physics elements-of-competence specifically required by the clinical and research contexts will be included. ${ }^{11}$

3. Owing to the need of employability of First Cycle graduates, elements-of-competence necessary for effective and safe performance in the clinical context will be included at lower levels. ${ }^{39}$ 
Table 1 Evaluation questionnaire and results for the pilot inventory together with a summary of responses. In the table 'overwhelming majority' denotes a percentage of $85 \%$ or higher of the total number of respondents

\begin{tabular}{ll}
\hline Question & Response \\
\hline $\begin{array}{l}\text { Do you feel that the inventory covers all the } \\
\text { physics competences expected of a radiographer }\end{array}$ & $\begin{array}{l}\text { The overwhelming majority of respondents } \\
\text { answered 'yes' to this question. }\end{array}$ \\
\hline in your country? If not please suggest additional &
\end{tabular}

in your country? If not please suggest additional

elements-of-competence.

Are there any elements-of-competence included in the inventory, which you think should be deleted from the inventory? If yes please specify and explain.

Are there any elements-of-competence included in the inventory which you think should be moved from one level to another? If yes please specify and explain.

Do you feel that the inventory is flexible enough to be usable in your country? If not please explain.

Do you feel that the inventory is flexible enough to allow for future developments in the education of radiographers? If not please explain.

Please indicate any elements-of-competence that you feel are not sufficiently clear. Suggestions are welcome.

Do you think there would be problems in translating the inventory into your national language? If yes please explain.

The overwhelming majority of respondents answered 'no' to this question.

Several suggestions were made by the respondents. These were included in the final form of the inventory.

The overwhelming majority of respondents answered 'yes' to this question.

The overwhelming majority of respondents answered 'yes' to this question.

Suggestions made by the respondents were included in the final form of the inventory.

The overwhelming majority of respondents answered 'no' to this question.
4. The design will acknowledge that the role of the radiographer today encompasses the use of all common imaging modalities, ${ }^{26-30}$ but that the level of competence for particular modalities within particular cycles varies from one country to the other and indeed from one university to another. ${ }^{35,36}$

5. The competences will be formulated in a way to promote a consistent use of terminology across the modalities. This will guarantee an integrated approach to medical imaging and a more rapid acquisition of equivalent competences in other modalities (cross-modality transferability of competences).

6. The competences will be couched in precise, scientific and up-to-date terminology.

7. The inventory will be formulated to allow for future role and scientific developments. ${ }^{40}$ In particular as the number of medical imaging devices is changing rapidly the inventory will be devised in a way such that it would be applicable to future modalities. It has been reported that changes in imaging device technology would have the highest impact on the role of the radiographer. ${ }^{8}$

8. The inventory will not be over-prescriptive to prevent educator and student disempowerment with respect to curriculum content (Grundy S. ${ }^{41}$ cited in Rees CE. ${ }^{42}$ ), allow for diversity and permit the development of native solutions to local curricular targets. ${ }^{19,20}$

The above guiding principles point to the need for a multi-level inventory consisting of crossmodality elements-of-competence statements. Our inventory therefore was stratified into five levels, L1-L5, where L5 represents the highest level of educational and professional attainment. A higher level assumes acquisition of competences at lower levels. The original pilot inventory was based on three levels only, however, participants in the HENRE conference expressed desire for a higher number of levels and that these would span the whole range of radiography education. The cross-modality (or perhaps one should say modality-independent) nature of the competences is aimed at circumventing the perennial curriculum development problems of future coverage (trying to predict what modalities students may need to learn about in the future) and early obsolescence (as conventional imaging modalities are replaced by newer ones). ${ }^{8,40,43}$ Such a framework would also permit and promote flexible curriculum development, yet be robust and structured enough to guide teaching in a systematic manner. It will also guarantee usability throughout the European area and within all Tuning cycles. 


\section{Level descriptions}

The operational descriptions of the levels are shown in Table 2. The descriptions are based on a pragmatic and judicious blend of cognitive, experiential, and career-progression paradigms that incorporates aspects of the proposed cycle descriptors of the European Higher Education Area, ${ }^{19}$ the Bloom, Gagne and Marzano taxonomies, ${ }^{44-46}$ Benner's Novice-to-Expert model, ${ }^{47}$ the Career Progression Framework of the Society and College of Radiographers (UK) $)^{3}$ and the Knowledge and Skills Framework of the National Health Service (UK), ${ }^{24}$ most of which have been extensively cited in the literature. These frameworks offer complimentary perspectives on competence and it was considered beneficial to mesh their better aspects into a single set of level descriptors. The benefits of integrating such stratification paradigms in the case of radiography and professional education in general have been discussed in the literature. ${ }^{48}$ This process ensures a level structure that would be acceptable to educationalists, professional bodies and employers alike. The levels were formulated to make them directly applicable to the medical imaging context as discipline-specific level descriptors have been found to be more suitable at the operational level, particularly in health professional education where students are learning a wide range of disciplines. ${ }^{42}$

\section{Use of the inventory in curriculum development}

The inventory can be used in diverse ways to guide curriculum development. The third column of the table in Appendix A illustrates how the inventory can be applied to help educators design content for the physics component of modules in a given imaging modality. We have illustrated this use of the inventory by applying it in the planning of a syllabus for the physics component of learning modules in CT. ${ }^{49-56}$ However, one can in a similar manner design a syllabus for any other present or future imaging modality. Table 3 demonstrates the use of the inventory in specifying physics outcome competences for a First Cycle programme for Europe. Second Cycle (Masters) modality-based programmes would include competences up to the L4 level in the specific modality. Modality-based Ph.D. programmes would include the competences up to the L5 level for that particular modality. The inventory can also be used as a checklist to evaluate the biomedical physics component of radiography programmes, the development of

Table 2 Operational descriptions of the competence levels used in structuring the inventory

Level Level description

L1 Competences necessary and sufficient for an appreciation of the diagnostic and monitoring capabilities of a medical imaging device, an awareness of risks to patient, self, colleagues and others from use of the device and for the effective and safe utilization of the device with test-objects or in simulated studies using anthropomorphic phantoms in a skills-lab context. Cognitive processes are mainly at knowledge retrieval and comprehension levels.

L2 Competences necessary and sufficient for supervised effective and safe use of a medical imaging device with patients, under written protocol, scope-of-practice restricted to studies that are basic, routine and predictable. Cognitive processes are mainly at knowledge retrieval and comprehension levels.

L3 Competences necessary and sufficient for minimally supervised effective and safe use of a medical imaging device with patients, under written protocol, scope widened to include studies that are complex or somewhat non-predictable. Supervised research using the device at a basic level. Cognitive processes are mainly at the analytic and knowledge-utilization levels.

L4 Competences necessary and sufficient for a fully autonomous effective, safe and economic use of a medical imaging device at the forefront of professional practice, comprehensive scope-of-practice in a wide variety of clinical contexts including studies that are complex and unusual, contingency preparedness, device management, allocation of resources, development of existing protocols and audits of practice, all totally guided by a best-evidence and ethical approach. Basic technology assessment and implementation of research studies in relation to new clinical applications of the device. Cognitive processes are mainly at the metacognitive and self-system thinking levels.

L5 Competences necessary and sufficient for a complete utilization of the scientific knowledge base underpinning the effective, safe and economical use of a medical imaging device in the clinical and research contexts including clinical service development, comprehensive technology assessment and the conceptualization, design and implementation of new device applications and user protocols. Cognitive processes are mainly at the metacognitive and self-system thinking levels. 
Table 3 Use of the competence inventory for setting possible minimum physics First Cycle competences for Europe $(\mathrm{c}=$ core programme, op $=$ options)

\begin{tabular}{|c|c|c|c|c|c|c|}
\hline Imaging modality & $\mathrm{L} 1$ & $\mathrm{~L} 2$ & L3 & L4 & L5 & Notes \\
\hline General projection radiography & c & c & c & & & Film and/or digital sensor \\
\hline Mammography & c & c & c & & & Film and/or digital sensor \\
\hline Dental radiography & c & c & c & & & Film and/or digital sensor \\
\hline General fluoroscopy & c & c & c & & & Image intensifier and/or digital sensor \\
\hline Angiography & c & & & & & Image intensifier and/or digital sensor \\
\hline Interventional fluoroscopy & c & & & & & Image intensifier and/or digital sensor \\
\hline CT & c & c & op & & & Sequential and/or multislice-spiral \\
\hline USI & c & c & op & & & Including Doppler \\
\hline MRI & c & c & op & & & \\
\hline RNI (planar) & c & c & op & & & \\
\hline SPECT & c & & & & & \\
\hline PET & c & & & & & \\
\hline Bone densitometry & c & & & & & \\
\hline
\end{tabular}

programme competence catalogues and curriculum mapping, irrespective of whether the curriculum is discipline-based or integrated, presentation-based or problem-based.

\section{Conclusions}

The deconstruction of general Subject Specific Competences into elements-of-competence and the construction of discipline-based inventories are essential in the systematic development and delivery of competence-based curricula. One of the most important uses of such inventories is that of a checklist to ensure that all essential elements-ofcompetence of broad general competences are included within the curriculum (whether discipline-based or integrated, presentation-based or problem-based) and that all are assessed. With regard to the latter, further work is required with respect to student performance criteria that would be tagged to the elements-of-competence and to find effective ways of integrating the physics assessment within comprehensive radiography assessments. ${ }^{57-59}$ This would convert the inventory into a competence acquisition assessment tool for purposes of student assessment and programme evaluation. It is suggested that the methodology used in the evolution of the inventory be applied to the development of inventories of elements-of-competence for other learning domains within radiography and other health professional curricula.

\section{Acknowledgements}

The authors would like to thank Patrick $C$. Brennan (University College Dublin) for correspondence regarding the role of the biomedical physics educator in diagnostic radiography education.

The authors would also like to thank V. Challen (HENRE project leader) and M. Dow (HENRE project co-ordinator) for their support during the project.

The authors wish also to thank the following HENRE members and others for submitting curricula: R. D. Royle (University of Salford, UK), Viggo Kristensen (University College Tromso, Norway), Mojca Medic, (University of Ljubljana, Slovenia), Alison Wright (Suffolk College, UK), Steven Patefield (St Martin's College, UK), Harold Clarke (University of Portsmouth, UK), Paul Bezzina (University of Malta), John H. Duijsings (Fontys University of Professional Education, Eindhoven, The Netherlands), Kate Matthews (University College Dublin, Republic of Ireland), R. J. Winder, (University of Ulster, UK), Rubim Santos (Escola Superior de Tecnologia da Saude de Porto, Portugal), Francisco Alves (Escola Superior de Tecnologia da Saude de Coimbra, Portugal), Leos Navratil (University of South Bohemia, Czech Republic), Piotr Lass (Medical University of Gdansk, Poland), Susanne Huber (Ludwig Maximilian University, Munich, Germany), Kent Fridell (Karolinska Universitet, Stockholm, Sweden), Vytenis Punys (Kaunas University of Technology, Lithuania), Mol Hendrikus (European Institute of Higher Education, Brussels), Gianni Pellicano (University of Florence).

Thank you also to the following HENRE members for extensive suggestions during the evaluation of the pilot inventory: J. McConnell (St Martin's College, UK), V. Punys (Kaunas University of Technology, Lithuania), M. Vosper (University of Hertfordshire, UK), J. Peeters (Fontys School for Health Professions, The Netherlands), F. Zarb (University of Malta). 


\section{Appendix A}

The inventory for biomedical physics curricula for diagnostic radiography

\begin{tabular}{|c|c|c|}
\hline Element-of-competence & Notes & $\begin{array}{l}\text { Illustrative syllabus content supporting } \\
\text { the particular element-of-competence } \\
\text { in the case of } \mathrm{CT}\end{array}$ \\
\hline
\end{tabular}

Level 1

Define and explain the physical property/ properties of tissue, which the device measures and images, including any variables impacting the value of these properties.

List and explain target imaging outcomes (in terms of image quality criteria ${ }^{34}$ ) relevant to diagnostic or monitoring effectiveness.

List and explain the target safety outcomes (in terms of safety criteria in relation to patient, user, colleagues and others) anticipated when using the device with respect to physical health hazards.

List and operationally define suitable imaging device performance indicators appropriate for users of the device and their relation to target image quality or safety criteria.
Tissue contrast is defined as difference in the physical property measured and imaged by the device. This is to be distinguished from image contrast that is difference in grey-scale level on the film or monitor.

The word 'target' emphasises that the eventual choice of device and protocol should be determined by image quality criteria determined prior to the actual exposure. 'Physical health hazards' include ionising radiation, mechanical, electrical, acoustic, ultrasonic, magnetic, electromagnetic hazards and elevated body temperatures.

An imaging device performance indicator is a measurable objective quantity that presents an indication of the extent to which a device is performing as it should, when compared to agreed standards. Performance indicators are defined in a way that they are associated with one or more image quality or safety criteria. Include basics of instrument science concepts: accuracy, noise, measurement uncertainty, precision, SNR, stability, need for calibration, instrument structure in terms of sensor signal-processor and output-device, qualitative harmonic Fourier signal analysis, filters, line-spread-function and modulation-transfer-function, digitisation of signals, bit-depth etc. However, concepts should be restricted to those relevant to imaging.
A CT scanner measures the attenuation coefficient of voxels in a slice (conventional CT) or volume (multislice-spiral CT) of patient. Conversion to CT number scale. Tissue contrast is difference in CT-number of different tissues. Dependence of CTnumber on voxel electron density (atom density and atomic number) and beam energy ( $\mathrm{kV}$, filtration).

Examples of image quality criteria for CT are visualisation, reproduction and visually sharp reproduction of anatomical structures/details of interest. ${ }^{50}$

Target safety criteria with respect to the patient include: doses at or below diagnostic reference levels, no damage to eyes from localisation lasers, avoidance of electric hazards. Target safety criteria with respect to the user are: near-zero occupational dose, avoidance of electric shock hazards. Examples of performance indicators for CT associated with image quality criteria are: spatial resolution in the scan plane (in terms of line pairs, LSF and MTF), spatial resolution in the direction of the axis of rotation (expressed as nominal slice thickness in the case of sequential CT, linepairs, LSF and MTF in the case of multislice-spiral), pixel noise (expressed as the standard deviation of pixel CT values in a water phantom image), contrast resolution, CT-value uncertainty, homogeneity (also known as uniformity) and absence of artefacts and distortion. ${ }^{49}$ Performance indicators associated with patient dose criteria are: weighted CTDI and dose-lengthproduct. ${ }^{50-51}$ Examples of relationships between performance indicators and image quality or safety criteria: spatial resolution and sharpness, noise and reproduction of small detail, dose-lengthproduct and patient effective dose. 
Appendix (continued)

\begin{tabular}{|c|c|c|}
\hline Element-of-competence & Notes & $\begin{array}{l}\text { Illustrative syllabus content supporting } \\
\text { the particular element-of-competence } \\
\text { in the case of CT }\end{array}$ \\
\hline $\begin{array}{l}\text { Describe and explain the } \\
\text { general structure and } \\
\text { functioning of the device } \\
\text { including user controls and } \\
\text { settings for both image } \\
\text { acquisition and } \\
\text { reconstruction. }\end{array}$ & $\begin{array}{l}\text { Include only details necessary for } \\
\text { the clinical situation. }\end{array}$ & $\begin{array}{l}\text { Avoid unnecessary details such as } \\
\text { generations of CT scanners, } \\
\text { reconstruction algorithms. For spiral } \\
\text { explain briefly meaning of z- } \\
\text { interpolation. A list of scan parameters } \\
\text { for sequential CT can be found here. }{ }^{49} \\
\text { For spiral-multislice CT include also } \\
\text { pitch and replace scan increment by } \\
\text { reconstruction increment. Include the } \\
\text { advantages of retrospective choice of } \\
\text { image position, scan increment and } \\
\text { slice thickness in spiral. }{ }^{49}\end{array}$ \\
\hline $\begin{array}{l}\text { Explain device design } \\
\text { variables which impact } \\
\text { device performance } \\
\text { indicators (and hence } \\
\text { image quality or safety } \\
\text { criteria) at a level } \\
\text { appropriate for users. }\end{array}$ & $\begin{array}{l}\text { Consider each performance } \\
\text { indicator in turn and list the device } \\
\text { design variables that impact the } \\
\text { particular performance indicator. } \\
\text { Concentrate on those variables that } \\
\text { can be controlled by the } \\
\text { radiographer. }\end{array}$ & $\begin{array}{l}\text { Examples: the main device design } \\
\text { variables which impact spatial } \\
\text { resolution in the scan plane are focal } \\
\text { spot size, focus to detector distance } \\
\text { and minimum focus to isocentre } \\
\text { distance, maximum reconstruction } \\
\text { matrix size and minimum } \\
\text { reconstruction field-of-view size } \\
\text { (relationship to patient voxel size, } \\
\text { zoom facility), number of projections } \\
\text { per rotation, availability of high-pass } \\
\text { image filters, detector spacing. }{ }^{49}\end{array}$ \\
\hline $\begin{array}{l}\text { Explain limitations and } \\
\text { artefacts of the device and } \\
\text { their impact on } \\
\text { performance indicators at }\end{array}$ & $\begin{array}{l}\text { Artefacts are defined as systematic } \\
\text { inaccuracies between values } \\
\text { measured by the device and the } \\
\text { actual values in the imaged object. }\end{array}$ & $\begin{array}{l}\text { Examples of limitations of CT: subjects } \\
\text { of non-circular cross-section, motion } \\
\text { artefacts owing to finite speed of } \\
\text { rotation etc. } 49\end{array}$ \\
\hline
\end{tabular}

Derivations of equations are not required.

From a device perspective protocols are designed to ensure that device performance indicators are not impacted negatively, to reduce the effects of the limitations of the device and eliminate or reduce risk to all concerned. It is important to realise that attempts to improve one performance indicator may lead to degradation of another and/or an increase in risk.
Example: the main protocol design variables which impact spatial resolution in the scan plane are focus to isocentre distance, application of high pass image filters, reconstruction matrix size, reconstruction field-ofview size, use of zoom, application of bolus around patient to improve shape of cross-section. Attempts to increase scan plane spatial resolution by reducing the reconstruction field of view or increasing the reconstruction matrix size will lead to an increase in pixel noise and lowering of contrast resolution which may necessitate an increase in $\mathrm{mA}$ and hence DLP. ${ }^{49,51}$ Similarly, use of high-frequency filters for increasing spatial resolution (sharpening filters) will increase visibility of pixel noise. ${ }^{49}$ 
Appendix (continued)

Element-of-competence

Notes

Illustrative syllabus content supporting

the particular element-of-competence

in the case of CT

Demonstrates ability to apply

commonly used image

processing and post-

processing procedures for

image enhancement.

Explain user options for at least one commercially available device.

Discuss qualitatively riskbenefit issues.

Compare at a basic level the device with devices used in other modalities in terms of effectiveness and safety.

\section{Level 2}

Demonstrates performance of L1 competences at a level that would ensure understanding of and strict adherence to protocols.

Lists and explains the physical basis of any contraindications in the use of the device.

Demonstrates knowledge of $\mathrm{EU}$ and national legislation, recommendations and regulations regarding the use of the device.

Demonstrates understanding of the physical principles underpinning the effective and safe use of any ancillary medical devices.

Demonstrates safe disposal of non-reusable ancillary medical devices.

Demonstrates awareness that an imaging device should be checked before use (daily quality control), cared for during use and left in a condition for subsequent use by self or others.
Film and/or digital images.

Magnification, zooming, windowing, choice of image filters as specified in protocols.

This should be done with the help of a user manual so that students become familiar with reading manuals.

Emphasise the complementary nature of imaging modalities and the fact that each modality provides a unique window into the body.

Including any calculations necessary to adjust the protocol to particular client groups.

In particular though not exclusively those regarding ionising radiation.

Imaging software is considered as a device ancillary to imaging devices. ${ }^{33}$ Which devices are considered as ancillary is determined locally. For example contaminated vials and syringes in radionuclide imaging.

Quality control is the systematic 'constancy testing' of performance indicators and associated device parameters. this reference. ${ }^{49}$ More scan parameters than given in the list may be available for particular scanners (for example gantry tilt angle, partial scan).

$\mathrm{CT}$ is a high dose technique. Special care in justification and optimisation is necessary particularly for women of child-bearing age and children. ${ }^{51}$ Discuss in particular the complementary nature of CT and MRI.

For example adjustments of $\mathrm{mA}$ in paediatrics.

There are no absolute contraindications for $\mathrm{CT}$, however, great care is required in justification when it comes to pregnant patients and children. Where possible alternative non-ionising modalities should be used. ${ }^{51}$

Good references on radiation protection and dosimetry considerations in $\mathrm{CT}$ can be found in ICRP documents. ${ }^{51}$

For example contrast media injectors, ionization chambers for CTDI measurement, ECG for gated studies.

For example disposal of non-reusable contrast media injector syringes.

Good references for quality control of CT can be found in the literature. ${ }^{49,52,53}$
For a list of scan parameters consult 
Appendix (continued)

\begin{tabular}{|c|c|c|}
\hline Element-of-competence & Notes & $\begin{array}{l}\text { Illustrative syllabus content supporting } \\
\text { the particular element-of-competence } \\
\text { in the case of CT }\end{array}$ \\
\hline
\end{tabular}

Describes the impact on

performance indicators

arising from device

malfunction, inappropriate

protocol and device misuse

including any artefacts

arising from these within

their scope-of-practice and

local procedures for

reporting such malfunctions.

Demonstrates ability to

measure or calculate

recommended indicators of

risk and compare to

established diagnostic

reference levels.

\section{Level 3}

Demonstrates performance of $\mathrm{L} 1$ and $\mathrm{L} 2$ competences at a level that would require minimum supervision when using the medical imaging device with patients, scope-of-practice widened to include studies that are complex or somewhat nonpredictable.

Explain the physical mechanism of tissue contrast enhancement by contrast media.

Demonstrates skill in basic routine preventive maintenance and more advanced quality control appropriate for users.

Demonstrates understanding of and ability to follow written contingency procedures.

\section{Level 4}

Demonstrates L1-L3 competences at a level expected of a user at the forefront of professional practice.

Ability to formulate procurement plans for the device in terms of performance indicators and associated specifications required by the clinical needs.
Which studies are considered 'complex' and 'somewhat nonpredictable' will be determined locally. The necessary extensions in the elements-of-competence for such cases are derived by competence analysis.

Not applicable to radionuclide imaging.

Weekly and monthly QC.

Explain the set of contingency procedures used in the actual practice setting. Evaluate and critically compare with others from literature.
Good discussions on artefacts in CT can be found in the literature. ${ }^{49}$ There are also many good sites on the web.
Methods for measurement of CTDI and calculation of DLP can be found in various documents. ${ }^{49,51}$
Which studies are considered 'complex' and 'somewhat nonpredictable' for CT will be determined locally. The necessary extensions in the elements-of-competence for such cases are derived by competence analysis.

CT contrast media are mainly iodine based. Explain increased attenuation coefficient of such media.

Good references for quality control of CT can be found here. ${ }^{49,52,53}$

Explain the set of contingency procedures for CT used in the actual practice setting. Evaluate and critically compare with others from literature.
Evaluation and comparison of performance indicators and associated parameters from different manufacturers.
Evaluation reports of $\mathrm{CT}$ scanners can be purchased or downloaded freely from the Internet. ${ }^{54}$ 
Appendix (continued)

Element-of-competence

Notes

Illustrative syllabus content supporting the particular element-of-competence in the case of CT

Demonstrates advanced skills in

preventive maintenance and quality control of the device appropriate for users.

Ability to identify and correct causes of below target image quality and safety criteria.

Demonstrates physics knowledge utilization in adjusting protocols to the needs of particular clients in studies which are complex, unusual, beyond-protocol and non-predictable.

Demonstrates ability to conduct risk assessment and develop contingency procedures.

Demonstrates the physics knowledge utilization necessary to carry out advanced applications of the device.

Demonstrates the physics knowledge utilization necessary to manage image archiving and communication systems.

Ability to liaise with biomedical physicists in the development of imaging services (device and dose management, image quality improvement, clinical audits).

Demonstrates the physics knowledge utilization and the scientific attitude necessary for full effective, safe and economical use of the device in the coordination and implementation of clinical and research programmes.

\section{Level 5}

Demonstrates understanding of the underpinning physical (including the supporting mathematical) knowledge necessary to envisage new clinical and research applications for the device and be able to liase fully with biomedical physics - engineering professionals in the development of these applications.

Ability to recognize ethical and economic issues regarding the device in research and service development initiatives.
It is not necessary to include correction of causes requiring advanced physics expertise.

Both patient and occupational risk. Creating a culture of safety.

DICOM, compression and effects on image quality, PACS etc.

Procurement, installation, acceptance testing of new devices, evaluate device specifications, QC protocol development etc.

The emphasis here is on a complete scientific attitude to devices. How can one get the most out of this device yet still keep risk to acceptable levels?

Basics of the mathematics of image reconstruction and processing, quality control etc with emphasis on those aspects required for the particular research project. Research papers which include underpinning physics should be critically analysed.

For example quantitative risk-benefit analysis, equitable use of resources, the importance of making full use of the capabilities of a device, EU risk classes for medical devices. ${ }^{33}$
Good references for quality control of CT can be found in the literature. ${ }^{49,52,53}$

$\mathrm{CT}$ angiography, interventional, endoscopy, multiplanar reformatting, $3 \mathrm{D}$ reconstruction etc.

In particular show examples of the effects of different levels of compression on CT images.

Look up the following references which are quite comprehensive. ${ }^{49-56}$

Basics of mathematics of image reconstruction and processing in $\mathrm{CT}$ (image reconstruction from projections, Radon transformation, convolution integral, image transforms, image filters etc).

$\mathrm{CT}$ is a high dose procedure. Guidance on exposures in biomedical research can be found here. ${ }^{55}$ Owing to the high doses $C T$ is in the higher risk classes defined by the Medical Devices Directive. ${ }^{33,55}$ 


$\begin{array}{lll}\begin{array}{l}\text { Appendix (continued) } \\ \text { Element-of-competence }\end{array} & \text { Notes } & \begin{array}{l}\text { Illustrative syllabus content supporting } \\ \text { the particular element-of-competence } \\ \text { in the case of CT }\end{array} \\ \begin{array}{l}\text { Ability to recognize technical and } \\ \text { ethical deficiencies in } \\ \text { documentation and legislation }\end{array} & \begin{array}{l}\text { Available documentation and } \\ \text { legislation should be critically } \\ \text { regarding medical devices }\end{array} & \\ \begin{array}{l}\text { Apply physics knowledge to the } \\ \text { technical aspects of a healthcare } \\ \text { technology assessment report for } \\ \text { the device. }{ }^{37}\end{array} & \begin{array}{l}\text { A health technology assessment } \\ \text { for CT (though limited to dose } \\ \text { considerations only) can be found } \\ \text { Please address any feedback regarding the above inventory to Carmel J Caruana (carmel.j.caruana@um.edu.mt). All suggestions } \\ \text { that are adopted will be acknowledged in future versions of the inventory. }\end{array}\end{array}$

\section{References}

1. College of Radiographers. A curriculum framework for radiography. London: CoR; 2003.

2. Pratt S, Adams C. How to create a degree course in radiography: a recipe. Radiography 2003;9:317-22.

3. College of Radiographers. A strategy for the education and professional development of radiographers. London: CoR; 2002.

4. Quality Assurance Agency for Higher Education (UK). Benchmark statements: health care programmes: radiography. Gloucester: Quality Assurance Agency for Higher Education; 2001.

5. Payne K, Nixon S. External influences on curriculum design in radiography degrees. Radiography 2001;7:249-54.

6. Price R, High J, Miller L. The developing role of the radiographer: issues affecting the future curriculum. London: University of Hertfordshire; 1997.

7. Williams PL, Berry JE. What is competence? A new model for diagnostic radiographers: Part 1. Radiography 1999;5: 221-35.

8. Williams PL, Berry JE. What is competence? A new model for diagnostic radiographers: Part 2. Radiography 2000;6:35-42.

9. Saba PR, Poller WR. Physics for radiologists: now more than ever! Acad Radiol 1999;6:261-3.

10. Balter S. Why (continue to) study physics? [editorial]. Radiographics 1992;12:609.

11. Hendee WR, Frey GD, Dixon RL. Point/counterpoint: physics concepts that cannot be explained from a clinical context should be omitted in physics courses for radiologists. Med Phys 2002;29:255-7.

12. Hendee WR, Dennis M, Rzeszotarski M. Point/counterpoint: to prepare radiology residents properly for the future, their physics education should be expanded in breadth and depth, and should be more quantitative and mathematically-based. Med Phys 2003;30:1955-7.

13. Dendy PP. Syllabus for a course in 'Diagnostic Imaging physical and biological aspects' for doctors undergoing specialist training in radiology. Available from: http:// www.efomp.org/docs/ear_syll_rads.html. [retrieved 08.04.05].

14. Barnes JE, Berry PC, Dennis MJ. Report 64: a guide to the teaching of clinical radiological physics to residents in diagnostic and therapeutic radiology. Madison WI, US: Medical Physics Publishing on behalf of the American Association of Physicists in Medicine; 1999.
15. Harden RM, Crosby JR, Davis MH. AMEE guide no. 14: outcome-based education: Part $1-$ an introduction to outcome-based education. Med Teach 1999;21:7-14.

16. Smith SR, Dollase R. AMEE guide no. 14: outcome-based education: Part 2 - planning, implementing and evaluating a competency-based curriculum. Med Teach 1999;21:15-22.

17. Harden RM. Developments in outcome-based education. Med Teach 2002;24:117-20.

18. European Commission: Directorate-General Environment. Radiation Protection 116: guidelines on education and training in radiation protection for medical exposures. European Communities; 2000.

19. Bologna Working Group on Qualifications Frameworks. A framework for qualifications of the European higher education area. Available from: http://www.bolognabergen2005.no/Docs/00-Main_doc/050218_QF_EHEA.pdf; 2005 [retrieved 03.04.05].

20. Tuning documentation can be found on the web-sites of the two co-ordinating universities: University of Groningen (http://www.let.rug.nl/TuningProject/index.htm) or University of Deusto (Bilbao) (http://www.relint.deusto.es/ TuningProject/index.htm).

21. Higher Education Network for Radiography in Europe (HENRE). Relevant documentation can be found on the HENRE project website at http://www.henre.co.uk.

22. Health Professions Council. Standards of proficiency: radiographers. London: HPC; 2003.

23. Skills for Health (UK). Clinical imaging standards. Available from: http://www.skillsforhealth.org.uk [retrieved 03.04.05].

24. Department of Health (UK). The NHS knowledge and skills framework (NHS-KSF) and the development and review process [final draft 2004] Available from: http://www.dh. gov.uk/assetRoot/04/09/08/61/04090861.pdf. [retrieved 07.04.05].

25. Manning D, Brian Bentley $\mathrm{H}$. The consultant radiographer and a doctorate degree. Radiography 2003;9:3-5.

26. Patterson AM. Role development - towards 2000: a survey of role developments in radiography. London: College of Radiographers; 1995.

27. Hogg $P$, Williams $P$, Norton $S$. Extended roles of radiographers working in nuclear medicine: a survey of current practice. Radiography 1997;3:179-90.

28. European Association of Nuclear Medicine. Competencies for the European nuclear medicine technologist. Available from: http://www.eanm.org/about_eanm/about_tgc_tech/ compro_compets.html [retrieved 09.04.05]. 
29. Prime NJ, Fernando R, Miller L, Mitchell L. The development of occupational standards in the practice of diagnostic ultrasound: Part 1, background. Radiography 1999;5:215-20.

30. Moller JM, Larsen L, Bovin J, Lausten GS, Hasselqvist M, Jensen CM, et al. MRI diagnosis of fracture of the scaphoid bone: impact of a new practice where the images are read by radiographers. Acad Radiol 2004;11:724-8.

31. Council Directive $96 / 29 /$ Euratom of 13 May 1996 laying down basic safety standards for the protection of the health of workers and the general public against the dangers arising from ionizing radiation. Off J 29/06/1996;L 159:0001-114.

32. Council Directive $97 / 43 /$ Euratom of 30 June 1997 on health protection of individuals against the dangers of ionizing radiation in relation to medical exposure, and repealing Directive 84/466/Euratom. Off J 09/07/1997;L 180:0022-27.

33. Council Directive 93/42/EEC of 14 June 1993 concerning medical devices. Off $J$ 12/07/1993; L 169:0001-43.

34. EUR. Optimisation of protection in the medical uses of radiation. [EUR 19793]. Luxembourg: Office for Official Publications of the European Communities; 2002.

35. International Society of Radiographers and Radiological Technologists. Conditions for the education of radiographers within Europe. ISRRT; 2003.

36. Lass P. Nuclear medicine technologist training in European countries. Eur J Nucl Med 2002;29:1083-90.

37. Norman GR, Gafni A, Stolberg HO, Moran LA. A core curriculum in the evaluative sciences for diagnostic imaging. Can Assoc Radiol J 1998;49:295-306.

38. Lass P. News and Reviews. Higher Education Network in Europe - Annual General Meeting. October 28-30, 2004, Marsascala Malta. Nucl Med Rev 2004;7:194.

39. Flinton D, Simpson R. A study into the expectations of managers regarding newly qualified radiographers within the department. Radiography 1996;2:161-2.

40. Ludvigsson J. A curriculum should meet future demands. Med Teach 1999;21:127.

41. Grundy S. Curriculum: product or praxis. London: RoutledgeFarmer; 1987.

42. Rees CE. The problem with outcomes-based curricula in medical education: insights from educational theory. Med Educ 2004;38:593-8.

43. Kell C, van Deursen R. The fight against professional obsolescence should begin in the undergraduate curriculum. Med Teach 2000;22:160.

44. Bloom BS, Engelhart MD, Furst EJ, Hill WH, Kratwohl DR, editors. A taxonomy of educational objectivities: the classification of educational goals. Handbook I: cognitive domain. New York: David Mckay; 1956.
45. Gagne RM. The conditions of learning. 3rd ed. New York: Holt, Rinehart \& Winston; 1977.

46. Marzano RJ. Designing a new taxonomy of educational objectives. Thousand Oaks, California: Corwin Press; 2001.

47. Benner P. From novice to expert: excellence and power in clinical nursing practice. Menlo Park: Addison-Wesley; 1984.

48. Yielder J. An integrated model of professional expertise and its implications for higher education. Int J Lifelong Educ 2004;23:60-80.

49. Kalender WA. Computed tomography. Munich: Publicis MCD Verlag; 2000.

50. EUR. Quality criteria for computed tomography [EUR 16262]. Luxembourg: Office for Official Publications of the European Communities; 1999.

51. International Commission on Radiological Protection. Publication 87: managing patient dose in computed tomography. Oxford: Pergamon Press; 2001.

52. Institute of Physics and Engineering in Medicine (IPEM). Report 77: recommended standards for the routine performance testing of diagnostic $X$-ray imaging systems. York: IPEM; 2005.

53. Institute of Physics and Engineering in Medicine (IPEM). Report 32: measurement of the performance characteristics of diagnostic imaging systems in medicine. Part III computed tomography. York: IPEM; 2003.

54. Medicines and Healthcare products Regulatory Agency (MHRA - UK). Evaluation reports for different CT scanners can be retrieved from http://www.impactscan.org/ bluecover.htm.

55. European Commission. Radiation protection 99: guidance on medical exposures in medical and biomedical research. European Communities; 1998.

56. Berry E, Kelly S, Hutton J, Harris KM, Roderick P, Boyce JC, et al. A systematic literature review of spiral and electron beam computed tomography: with particular reference to clinical applications in hepatic lesions, pulmonary embolus and coronary artery disease. Health Technol Assess 1999; 3(No.18). Available from: http://www.ncchta.org [retrieved 03.05.05].

57. Davis MH, Harden RM. Competency-based assessment: making it a reality. Med Teach 2003;25:565-8.

58. Rethans JJ, Norcini JJ, Baron-Maldonado M, Blackmore D, Jolly $\mathrm{BC}$, LaDuca $\mathrm{T}$, et al. The relationship between competence and performance: implications for assessing practice performance. Med Educ 2002;36:901-9.

59. Burchell H, Higgs T, Murray S. Assessment of competence in radiography education. Assess Eval High Educ 1999;24:315-26.

Available online at www.sciencedirect.com

science@direct 